2

\title{
Enhancing life-cycle integration through the application of Case-Based Reasoning to Quality Function Deployment
}

D.A. Adams ${ }^{1}$, C. Irgens ${ }^{1}$, E. MacArthur ${ }^{2}$ and B. Lees ${ }^{3}$.

${ }^{I}$ Faculty of Engineering, The University of the West of England, Bristol, BS16 1QY

${ }^{2}$ Department of Mathematics and Statistics.

${ }^{3}$ Department of Computing and Information Systems.

${ }^{2,3}$ University of Paisley, High Street, Paisley, PA1 2BE, UK.

${ }^{I}$ Contact: David Adams, Email: adam-

mm0@wpmail.paisley.ac.uk,

Phone: ++44141848 3553, Fax: ++441418483555.

\begin{abstract}
Quality Function Deployment (QFD) is a product development methodology that is primarily aimed at increasing customer focus throughout the product development process. One benefit of this approach is a more structured and visible decision making process which spans a number of life-cycle activities. In this way QFD is often regarded as a facilitator of life-cycle engineering techniques such as Concurrent Engineering.

One of the problems of QFD, however, is the scalability of the methodology: it is often impractical to remain true to the principles of the methodology when developing anything but the simplest of products. This suggests that some form of computational support for the QFD methodology, which leads to a more effective application of the principles advocated by the methodology, could be beneficial. If this is achieved, the effectiveness of life-cycle engineering activities within the organization should be increased.

The paper describes a prototype system that applies an artificial intelligence technique known as Case-Based Reasoning (CBR) to the QFD methodology.
\end{abstract}

\footnotetext{
'D. A. Adams will remain at his Paisley (Dept. of Mechanical Engineering) address until Sept. 1997 despite being affiliated to The University of the West of England.
}

Computer Applications in Production and Engineering. F. Plonka and G. Olling (Eds.)

(C) 1997 IFIP. Published by Chapman \& Hall 
Through this approach it is possible to evaluate decisions made at an early stage of the product life cycle in terms of other life cycle activities based on previous experience.

The prototype builds upon previous work which has resulted in practical experience of the contribution to life cycle engineering activities offered by the approach. This is reported upon in the paper.

\section{Keywords}

Concurrent Engineering, Life-cycle integration, Case-Based Reasoning, Quality Function Deployment

\section{INTRODUCTION}

Quality Function Deployment (QFD) is a market driven design and development methodology for products and services to meet or exceed customers' needs and expectations (Prasad, 1996). The methodology was developed in 1966 in Japan by Yoji Akao. Akao defined QFD as being "a method for developing a design quality aimed at satisfying the consumer and then translating the consumers' demands into design targets and major quality assurance points to be used throughout the production stage." (Akao, 1990).

The first industrial application of QFD methodology occurred at Mitsubishi's Kobe shipyard in Japan in 1972. Motivation for use of QFD at Kobe arose from a necessity of the company's products (ocean transportation vessels) to meet the market's requirements of high quality products coupled with stringent government regulations (Prasad 1996). Since this initial use of QFD, the methodology has grown in popularity (if only recently) in the western world. For example, Ford, General Motors, Chrysler, AT\&T, Proctor and Gamble, Hewlett-Packard, and Digital Equipment, have been reported (Prasad, 1996) to have used the methodology to some extent.

When successful, the benefits obtained from QFD practices have been reported as:

- increasing the level of team working including providing a communication platform for concurrent engineering (Prasad 1996, Sanchez et al 1993, Cohen 1995),

- reducing the time to market (ASQC/ASI 1992, Sanchez et al 1993),

- reducing the amount of re-work (Wilson and Greaves 1990), and

- increasing the quality of the product (Wilson and Greaves 1990, Aako 1990, Sullivan 1986, Hauser and Clausing 1988).

However, these benefits - or indeed successful adoption of QFD - are far from universal. Problems with QFD have arisen due to the subjectivity of decisions that are required in the process. This has been particularly evident at the first stage of the process where it is necessary to translate subjective customer statements into 
objective engineering measures (Sanchez et al 1993). Decisions taken at this stage are often found to be "arbitrary" and subject to the "whims" of the designer or design team (Franceschini and Rossetto 1995). Because of this, QFD can be a time consuming process (Cohen 1995) which can lead to a lack of the necessary (Akao 1990, Sullivan 1986) management and team buy-in. A further problem with QFD lies in the QFD paradox: although QFD is advocated as providing a platform for team working and concurrent engineering, the methodology is by definition a sequential stepwise process (see next section). Concurrent engineering, therefore, is not supported by the process of QFD itself but rather by the multifunctional team based activity that is required in the initial stages of the process. It is our experience that some organizations either fail to realize this, or realize this but do not have the necessary skills, expertise, or information infrastructure to apply the methodology successfully.

These issues have lead to the development of a computer-based approach primarily aimed at alleviating these difficulties in the QFD process. The approach utilizes Case-Based Reasoning techniques and is based upon the hypothesis that, if experience from QFD developments can be captured in some useful form, then this experience can be reused in future QFD developments that are in some way similar to previous developments. This will reduce the severity of some of the above problems by giving QFD decision makers a starting point from which to base their decisions based on what was done in similar situations. Therefore, when presented with a set of customer requirements to be satisfied, the QFD team will have available to them an easily accessible body of experience which may provide direction and advice based upon the solution steps, i.e. the QFD matrices, and rationale that were taken to achieve similar requirements in the past.

It would be unwise, however, to blindly use previous solution steps without some form of evaluation. The approach, therefore, utilizes feedback information as an evaluation of the solution based upon the solution's use. As will be discussed in the next section, this feedback information can come from a number of life-cycle stages with the final feedback coming from the customer. By utilizing feedback at the early stages of QFD, the approach effectively promotes and enhances life-cycle integration within the product development life-cycle.

\section{QUALITY FUNCTION DEPLOYMENT}

\subsection{QFD process}

In general, the process of QFD comprises four stages: Product Planning, Design Deployment, Process Planning, and Production Planning (Sullivan 1986, Ranky 1994, Sanchez 1993). Each of these stages consists of a translation process between the input to the stage and the output from the stage. The output from one stage is the input to the following stage. The initial input is the customer requirements with the final output being a set of production plans. These 
production plans should result in a manufactured product that reflects the customer's voice. The process is shown in Figure 1.

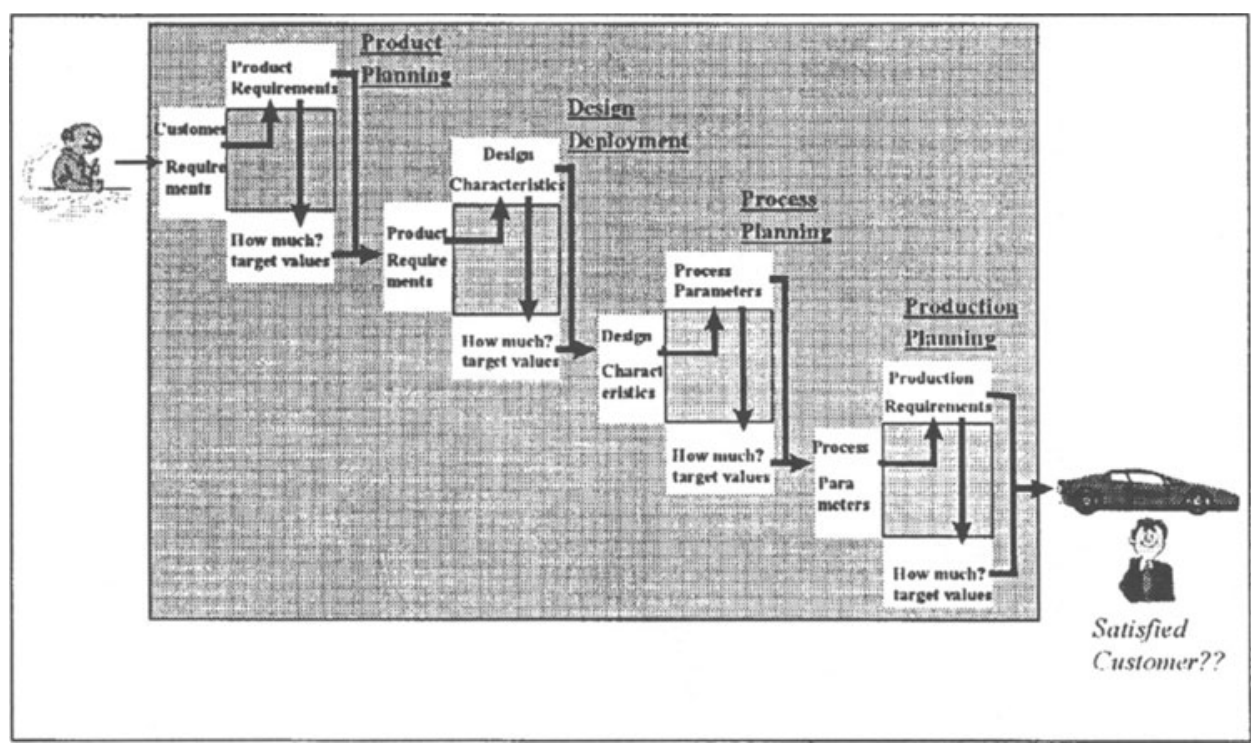

Figure 1 The QFD Process.

This process should be conducted by a multidisciplinary team with the assistance of a number of matrix-based charts. These charts serve as the means by which the customers' wants and needs are propagated though the product life-cycle and also as a focus for team activities. A matrix typically used at the first stage of the process, although applicable to each stage, is the House of Quality (Hauser and Clausing 1988, Sullivan 1986, Cohen 1995, Prasad 1996). This is shown in Figure 2. Use of the House of Quality (HoQ) is as follows (Adams et al 1996):

1. Obtain Customer Requirements and their degree of importance. ('Whats')

2. Determine any trade-offs between the customer requirements. (Requirements matrix)

3. Determine the required product characteristics. ('Hows')

4. Determine the relationships between the 'Whats' and the 'Hows'. This is called the Relationship Matrix.

5. Determine any trade-offs that may exist between product characteristics. This is done in the 'roof' of the HoQ and is known as the Correlations Matrix. 
6. Determine product goals or 'How Much'. In this area two values are derived. The first of these is a goal value for the particular product characteristic and the second is an importance weighting illustrating how important the achievement of the product characteristic is to achieving the customer requirements

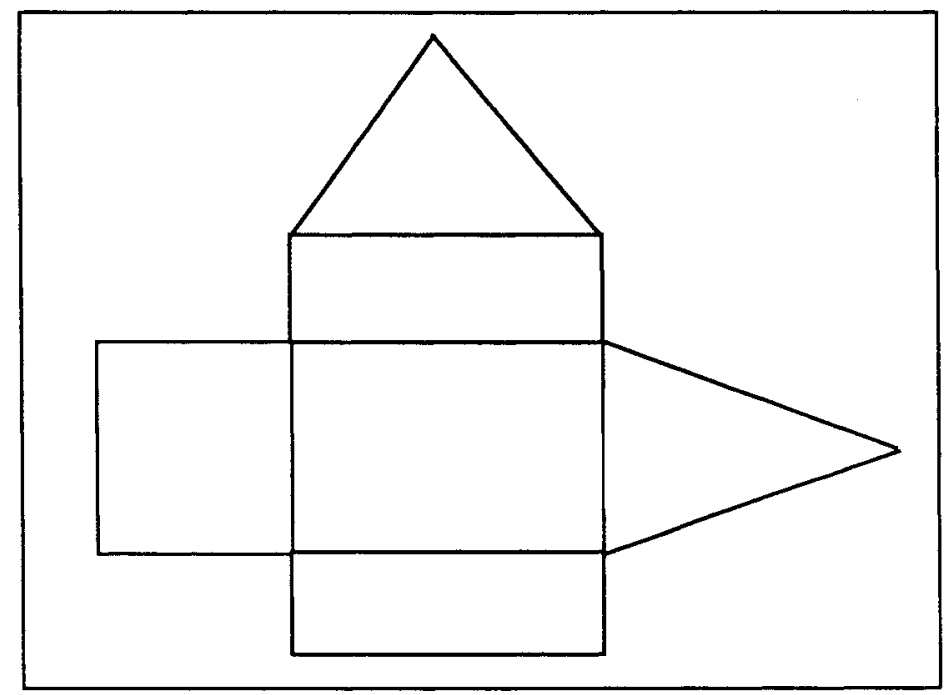

Figure 2 The House of Quality

The output from the HoQ, therefore, is a set of product characteristics with their target values and importance weightings. If the first stage has been conducted properly and thoroughly, by a multifunctional team, who understand both the customer and the capabilities of the organization, then the set of product characteristics should reflect the customer requirements and have all potential engineering bottleneck areas identified (Akao 1990). If this is the case, then the remainder of the development should incur no unforeseen difficulties. This, however, seldom occurs which results either in 'bad' decisions being taken downstream because of inappropriate product characteristics being assigned or back-tracking to previous stages to make changes. This process results in a body of feedback information - the flow of which is not modeled by the traditional QFD process shown in Figure 1 - which could be used beneficially in future QFD processes if captured and utilized.

\subsection{Life-cycle integration in QFD}

As mentioned above, there is normally a significant amount of feedback information which occurs informally within the QFD process. Possible feedback routes are shown in Figure 3.

As indicated in Figure 3, each stage of QFD - apart from the first one - could have feedback concerning any or all of the preceding stages. For example, 
problems discovered in the process planning stage may be due to decisions made in the design deployment stage. However, the decisions made in the design deployment stage are linked to the output from the first stage of the process which means that the decisions undertaken in this stage may be affected. The further the development progresses, the more possibilities for feedback occurs, until the product is eventually released onto the market. At this point the possibilities for feedback come from all internal sources as well as the external source of the customer. This feedback will be concerned with a deviation between what was expected and what was delivered. For the customer this will be a deviation from the expectations of the product and what was delivered, whilst internal sources of feedback will be concerned with a deviation with the expected output from the preceding stage and what was presented.

Each stage of the QFD process has as its customers all downstream activities as well as the consumer of the product. Making this more formal, (Prasad 1996) considers "voice of the customer" data $\left(D_{\text {voc }}\right)$ to be a function of "internal customers" $\left(D_{i c}\right)$, "external customers" $\left(D_{e c}\right)$, and "past and future customers" $\left(D_{p \&}\right)$. Prasad expresses this as:

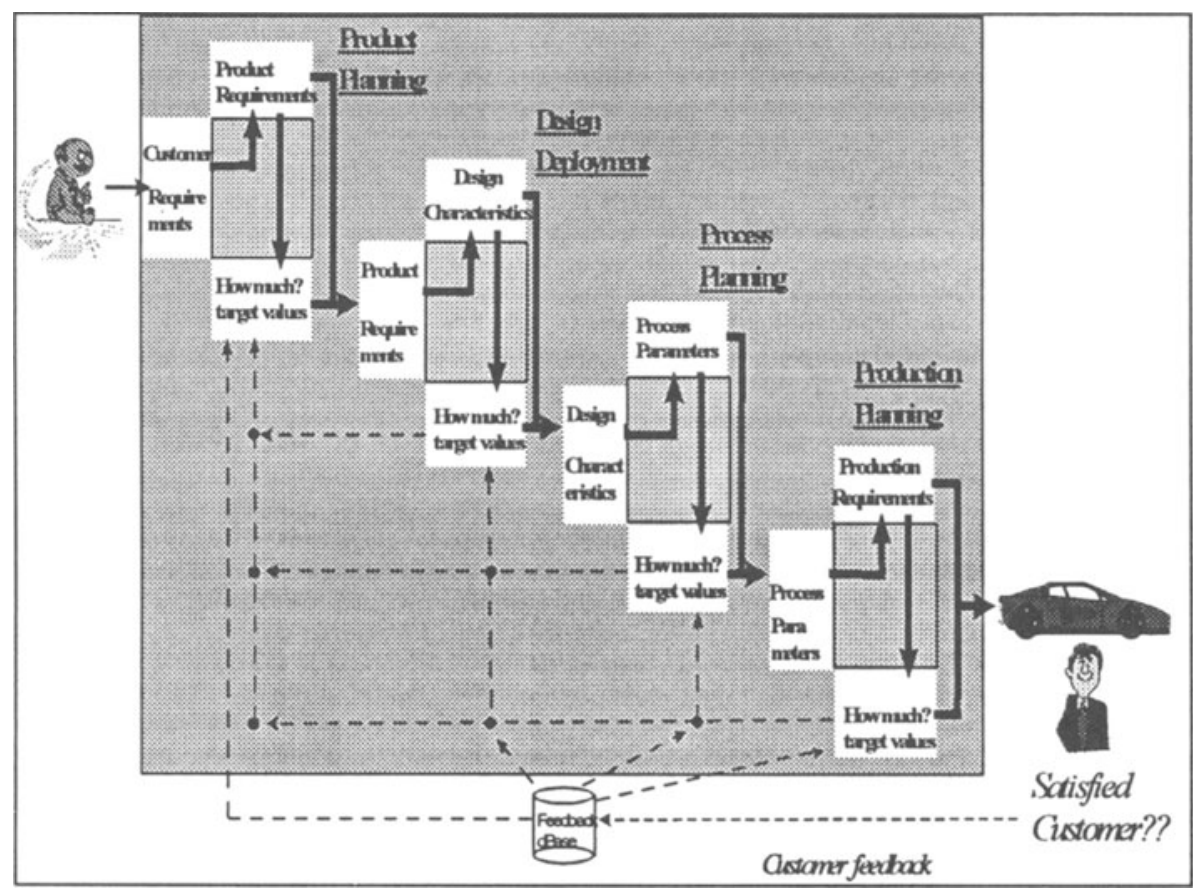

Figure 3 QFD with Feedback 
$\mathrm{D}_{\mathrm{voc}} \equiv f\left[\mathrm{D}_{\mathrm{ic}}, \mathrm{D}_{\mathrm{ec}}, \mathrm{D}_{\mathrm{p \& f}}\right]$

We extend this formalism by decomposing the internal and external customer data as follows:

$\mathrm{D}_{\mathrm{ic}}, \mathrm{D}_{\mathrm{ec}} \equiv f\left[\mathrm{D}_{\mathrm{pr}}, \mathrm{D}_{\mathrm{ps}}\right]$

where $D_{p r}$ relates to present customer (both internal and external) data, and $D_{p s}$ relates to past customer data. The past customer data can then be further decomposed to:

$\mathrm{D}_{\mathrm{ps}} \equiv f\left[\mathrm{D}_{\mathrm{r}}, \mathrm{D}_{\mathrm{s}}, \mathrm{D}_{\mathrm{f}}\right]$,

where $D_{r}$ relates to past requirements, $D_{s}$ relates to past solutions, and $D_{f}$ relates to past feedback.

By storing the past information, comprising the past requirements, past solutions and associated feedback, it is possible to use this information in making decisions about present requirements and their solutions. In this way downstream activities can be incorporated effectively into decision making at the initial stages of the product development life-cycle based on experience. In theory, therefore, this helps the QFD team take account of all life-cycle stages. The problem, however, is establishing similarities between past and present customer (internal and external) requirements. A computational technique known as Case-Based Reasoning offers significant potential to this approach.

\section{CASE-BASED REASONING}

\subsection{Background}

Case-based reasoning (CBR) is an artificial intelligence technique that has its roots in cognitive science research and the role of "remindings" in human reasoning (Schank 1982). The technique concentrates on the use of specific problem solving experiences in the solution of new - but similar - problems. Basically, CBR utilizes the characteristics of a problem situation to facilitate a "reminding" to a previous problem situation, or experience, that has similar characteristics. The solution to the previous problem is then reused either as a complete solution to the new problem or as a starting point to a new solution. For an general introduction to CBR see (Aamodt 1995, Kolodner 1993, Leake 1996, Watson 1995).

As an approach to computational reasoning, CBR has many advantages (Leake 1996, Watson 1995) which make it attractive. More interesting, however, are the benefits that successful implementation of CBR can offer the host organization. Althoff et al (Althoff et al 1995) have identified the following potential benefits of utilizing CBR within an organizational setting: 
- delivering more consistent decisions throughout the organization (assuming the system is used universally);

- preserving the know-how of specialists by capturing their experience;

- transferring experience from the skilled specialist to the novice;

- building a form of corporate memory by sharing individual experience.

These benefits make CBR an ideal instrument for implementing the approach to QFD and, in turn, the integration of the life-cycle that has been discussed. A more detailed overview of how CBR is conducted is now given.

\subsection{The CBR Process}

The process of CBR is described in (Aamodt and Plaza 1994) as the CBR cycle. This is shown in Figure 4 and involves the following steps:

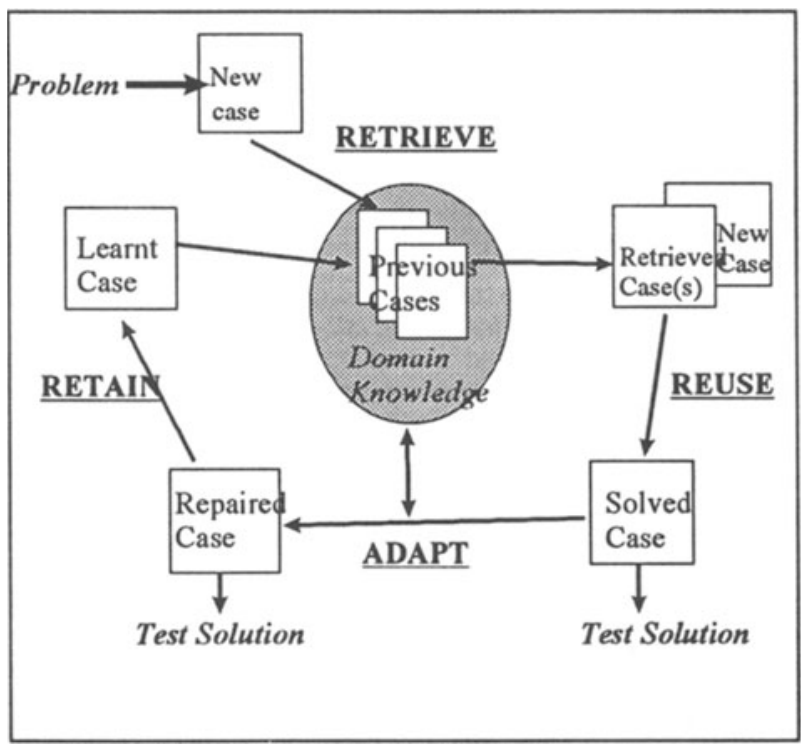

\section{Figure 4 - The CBR Cycle (Aamodt \& Plaza)}

1. Retrieve the most similar case(s) by using some form of similarity assessment measure.

2. Reuse the solution(s) in the retrieved case(s) as a starting point for solving the new problem. Test the solution at this point to evaluate the solutions worth.

3. Adapt the proposed solution in order to solve the new problem. Continually test and adapt the solution until a satisfactory solution is achieved. This may be aided by a body of domain knowledge.

4. Retain the significant parts of this experience for use in future problem solving. 
Any implementation of Case-Based Reasoning must take into consideration the above aspects. Each of these has attracted significant amounts of research activity from the computer science and cognitive science research communities. Discussion of these issues is out with the scope of this paper, however, the interested reader is directed to (Kolodner 1993).

A fundamental consideration in CBR, is the composition of the "case". Although this is application specific, the general composition of a case is described below.

\subsection{Case content}

A useful definition of a case is given in (Kolodner 1993):

"A case is a contextualised piece of knowledge representing an experience that teaches a lesson fundamental to achieving the goals of the reasoner." (Kolodner 1993)

A case is considered to be a specific experience which is internally representable by a computational machine. A case-base or case library is a collection of cases. It is from this library of cases, and in turn the specific cases themselves, that the reasoning in the process is facilitated. A critical factor, therefore, in the effectiveness of a CBR system, is the contents of each case which makes up the library.

In order to remain true to the definition given above, it is suggested (Kolodner 1993) that each case should consist of three major parts: (i) Problem/Situation description - this is the description of the problem needing solved and essentially defines the context of the experience or case, (ii) Solution - this is a description of the solution used to solve the problem and can include rationale and use domain knowledge (Aamodt and Plaza 1994). (iii) Outcome - this is the success or otherwise of the solution after it was applied to the problem and is the means by which the technique avoids repeating unsuccessful solutions.

Deciding the contents of each of the above parts is a major concern in the development of case-based systems.

\subsection{Some example CBR systems}

Case-Based Reasoning has found employment in a broad range and diversity of applications ranging from the very popular help-desk systems (e.g. Acorn and Walden 1992) to the more unique application of using CBR to simulate biological neural networks (Wendel 1993). The technique has also broken out of the confines of the research community and found many industrial applications. The first of these was by Lockheed Aerospace in Palo Alto, Califormia in 1990 (development began in 1987) (Hennessy and Hinkle 1992) with another notable application occuring within General Dynamics' Electric Boat Division (Simoudis 1992). 
An area that has received a substantial amount of attention by the CBR research community is that of the design task. This has resulted in a sub-area of CBR being established called Case-Based Design (CBD). For an overview of this area consult (Maher et al 1995). Examples of interesting CBD systems are CYCLOPS (Navinchandra 1988), Kritik-2 (Goel 1989), CADET (Sycara et al 1991), MIDAS (Domeshel et al 1994), and CADRE (Hua et al 1993).

\section{LIFE-CYCLE INTEGRATION USING CBR}

\subsection{Previous work: RA-IQSE}

The Revision Advisor - Integrated Quality Support Environment (RA-IQSE) (Irgens 1995), is a prototype system which uses CBR techniques to supply the early stages of the design process with experience-based information from previous developments. The system has a front-end and a back-end. The front-end provides the designers interface to the system and allows the designer to conduct design activities and request advice about the suitability or 'fitness-for-purpose' of the proposed design. The 'fitness-for-purpose' of the design is based on information entered via the back-end of the system. Here, data from testing, manufacturing, and warranty forms, are input for completed/in-service products. If advice is requested by the user, then the CBR mechanism locates a "similar" past design and uses the feedback information associated with the past design to provide advice in the creation of the new design.

The RA-IQSE project enforced the idea that ultimate quality is largely determined at the design stage and attempted to improve quality by making designers more aware of past product successes and failures. The prototype was implemented at an automotive parts manufacturer with positive results, the most significant of which was the acceptance by the part designers of the CBR technique.

\subsection{Proposed approach: applying CBR to QFD to enhance life-cycle integration}

For RA-IQSE, the front and back ends of the system were purposely built to achieve the system's goals. Similarly the underlying data structures and case representations were fixed and permitted no opportunities for receiving pertinent life-cycle information from sources other than the system feedback interface. Furthermore, at the front end of the system only tightly specified 'customer requirements' could be entered which were more akin to product characteristics within the QFD process. The designer then created a design based on these product characteristics and received advice of the proposed design. RA-IQSE, therefore, supported the second stage of the QFD process and avoided the first 
stage which is recognized as being the most crucial and difficult to complete (Sanchez et al 1993).

These factors contributed to the motivation for developing a new approach which continued the philosophy initiated with RA-ISQE but that attacks the problem with an extended set of goals. The ultimate goal of utilizing feedback information more effectively still remains. However, by adopting the full QFD process as a framework, the approach can achieve a greater focus upon the customer and encompass a greater span of the life-cycle more effectively. The greater focus on the external customer is achieved by making use of the approach at the first stage of the QFD process and is compounded by taking account of actual customer feedback once the product is in use. Through achieving this, the system provides the host organization with a customer responsive mechanism (Davis and Manrodt 1996).

In terms of internal customers, the new approach makes it far easier for feedback to be collated. In RA-IQSE, as mentioned above, the 'Quality Observations' had to be entered via the feedback interface regardless of their origin. This is not as convenient as the developed approach whereby the case is used to integrate information residing in independent databases dealing with the various stages of the life-cycle. In this way, the CBR component of the system may be seen as an integrating mechanism.

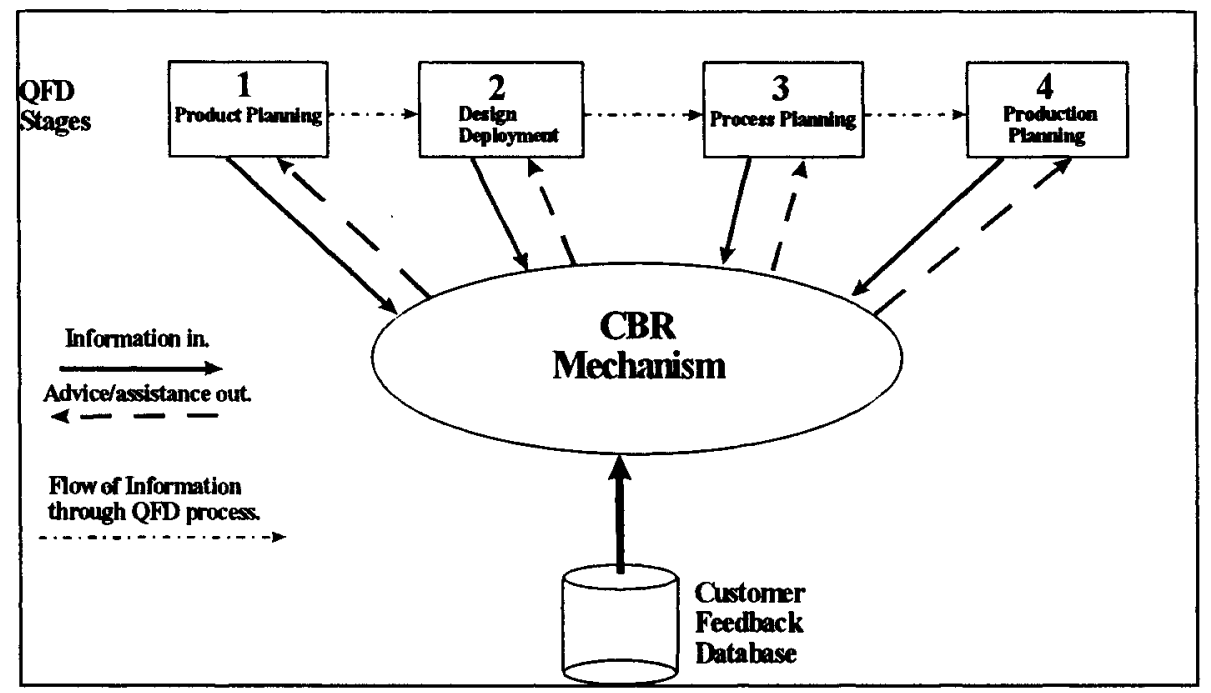

Figure 5 General Approach

The approach is illustrated in Figure 5 focusing in particular on the use of the CBR mechanism as a life-cycle information integrator. 


\section{PROTOTYPE IMPLEMENTATION}

\subsection{Prototype delineation}

A prototype implementation of the described approach is currently being constructed with the imposed limitations of only utilizing customer feedback information and relating this feedback to the initial stage of the QFD process. The rationale for utilizing customer feedback information is that such information reinforces the philosophical slant of QFD (i.e. getting 'close' to the customer) and therefore potentially offers the greatest benefit to the organization in general and the QFD process in particular. Furthermore, this information is frequently recorded by manufacturing organizations but is seldom utilized fully (Goodman et al 1996). The described approach makes significant utilization of this information.

The reason for only relating the customer feedback data to the first stage of the QFD process is two-fold. Firstly, this stage is the most subjective (Franceschini and Rossetto 1995) of all the QFD stages and as such has no underlying model against which to evaluate decisions. Therefore, specific feedback about a product after appropriate interpretation - may prove useful in evaluating decisions at the first stage. Secondly, the first stage of the QFD process effectively defines the product the customer will receive and thus is the most important of all the stages. Therefore supporting the first stage offers most leverage in terms of final product quality.

Despite these limitations life-cycle integration is still being achieved and - as argued - possibly being achieved over the life-cycle activities which lead to greatest customer satisfaction.

\subsection{Architecture}

The basic architecture of the prototype system is illustrated in Figure 6 . The current implementation of the system utilizes a House of Quality database at the start of the life-cycle and a customer feedback database in the later stages of the life-cycle. A knowledge-base is also used by the CBR mechanism. It is important to note that these databases are independent and have a purpose on their own. It is the CBR mechanism which acts as a collector and correlator of information through a case which is independent of both systems.

The architecture (Figure 6) greatly simplifies many of the issues relating to the case-based aspects of the approach. For a more detailed examination of how the CBR mechanism works see (Adams et al 1997). 


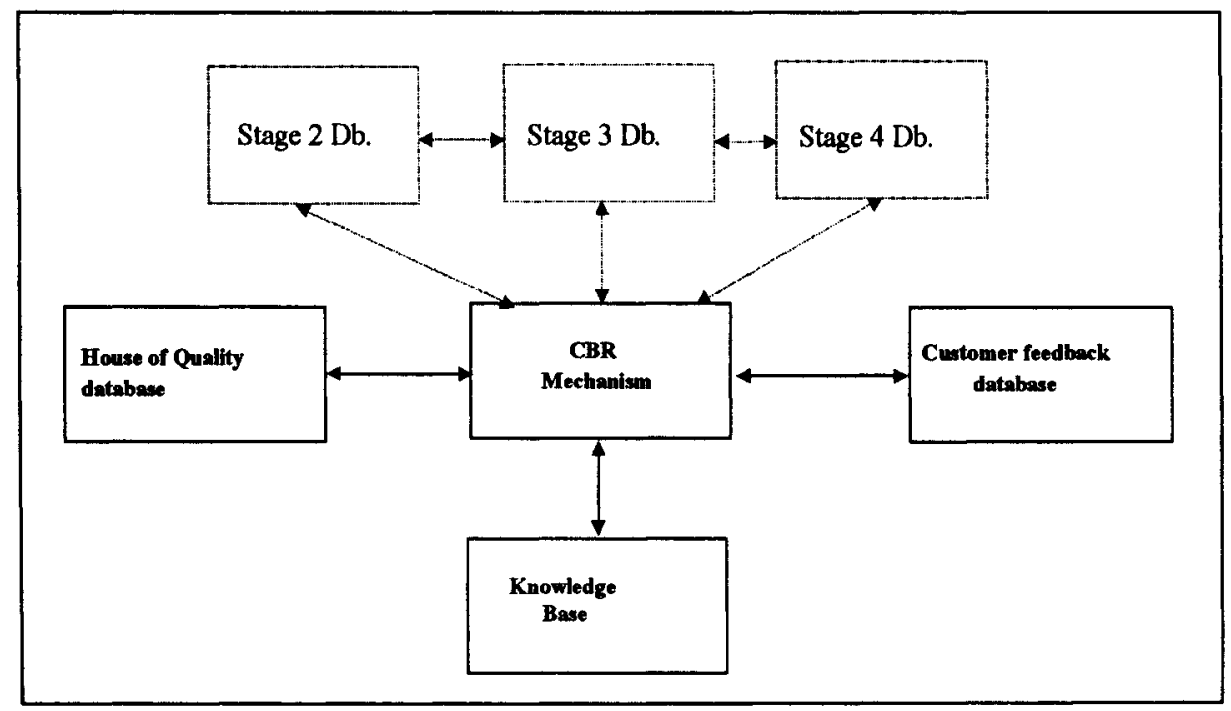

Figure 6 System Architecture

\subsection{System use}

Although the flexible nature of the system means that the user can interact with the system in many ways, a typical example of the system would operate as shown in Figure 7 and is described below:

1. The contents of the case are described as the situation for which advice is to be given - this may be range from an almost empty HoQ through to a completed HoQ.

2. Case identifying indices are assigned to the new case and a retrieval operation is performed on the case library.

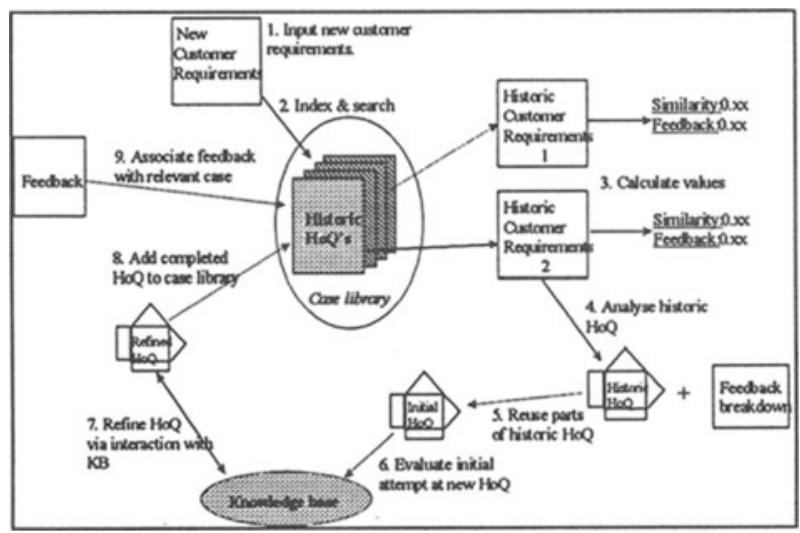

Figure 7 Typical user interaction

3. For each retrieved 
case two values are calculated: the similarity measure and the feedback assessment measure.

4. The retrieved cases are analysed and the parts of the cases which can be reused for the new case transferred.

5. An initial attempt at constructing the new HoQ is performed.

6. The result of 5 is evaluated for any constraint violations in the requirements, relations and correlation's matrices.

7. The new case is completed by providing solutions to the customer requirements that remain unsolved. This is achieved by allowing the user to select product characteristics that provide the functionality required. During this process continual evaluation is performed therefore allowing the user to see the effects of his/her decisions immediately.

8. The completed HoQ is then stored in the case library for future use.

9. Any feedback information that is received is interpreted and associated with the relevant case.

For an illustrative example of the system see (Adams et al 1996).

\subsection{SUMMARY AND FUTURE WORK}

It is anticipated that the approach described in this paper will offer significant benefits in the areas of continuous improvement of products and life-cycle integration. The first of these benefits being achieved essentially through the provision of the later. The approach follows the philosophical direction of our previous work on RA-IQSE but aims to extend and enhance the RA-IQSE work as has been described in the paper.

The prototype system that has been described is due for industrial evaluation in the Autumn of 1997. Based on the results achieved from the evaluation, the direction for future work on the approach will be established. This will be reported upon at the appropriate time.

\subsection{REFERENCES}

Aamodt, A., (1994) "Case-based Reasoning in Context: The Technology and its Impacts.", in Case-Based Reasoning: A new force in Advanced Systems Development, UNICOM Seminars, pp. 9-23, 27.

Aamodt, A., Plaza, E., (1994) "Case-Based Reasoning: Foundational Issues, Methodological Variations, and System Approaches.", AICOM, vol. 7, no. 1. Acorn, T. L., Walden S. H., (1992), "SMART: Support Management Automated Reasoning Technology for Compaq Customer Service", Proc. $4^{\text {th }}$ Innovative Applications of Artificial Intelligence Conference, CA. 
Adams, D. A., Irgens, C., Lees, B., MacArthur, E., (1996) "A case-based reasoning approach to QFD and product life-cycle information navigation -the potential of case outcome", VDI Berichte 1289, München.

Adams, D. A., Irgens, C., Lees, B., MacArthur, E., (1997) "Using case outcome to integrate customer feedback into the Quality Function Deployment process", $5^{\text {th }}$ German Workshop on Case-Based Reasoning, Bad Honnef, March 1997.

Althoff, K-D., Auriol, E., Barletta, R., Manago, M., (1995), "A Review of Industrial Case-Based Reasoning Tools", AI Intelligence.

Akao, Y. (Ed.), (1990), Quality Function Deployment: Integrating Customer Requirements into Product Design, Productivity Press.

ASQC/ASI, (1992), Transactions from the $4^{\text {th }}$ symposium on QFD, June 15-16, Nov., MI.

Cohen, L., (1995), Quality Function Deployment, Addison-Wesley Publishing.

Davis, F. W., Manrodt, K. B., (1996), "Customer-Responsive Management: The Flexible Advantage", Blackwell Publishers, Inc.

Domeshek, E. A., Herndon, M. F., Bennett, A. W., Kolodner, J. L., (1994), “A Case-Based Design Aid for Conceptual Design of Aircraft Subsystems", in Proc. of $10^{\text {th }}$ IEEE conference on Artificial Intelligence for Applications, Washington, 1994.

Franceschini, F., Rossetto, S., (1995), "QFD: The problem of comparing Technical/Engineering Design requirements", Research in Engineering Design, vol. 7, pp. 270-278.

Goel, A., (1989), Integration of case-based reasoning and model-based reasoning for adaptive design problem solving. $\mathrm{PhD}$, Dept. of Computer and Information Science, Ohio State University.

Goodman, J., DePalma, D., Broetzmann, S., (1996) "Maximizing the Value of Customer Feedback", Quality Progress, December 1996.

Hauser, J., Clausing, D., (1988), "The House of Quality", Harvard Business Review, vol. 66, no. 3, pp. 63-73.

Hennessy, D., Hinkle, D., (1992), "Applying Case-Based Reasoning to Autoclave loading", IEEE Expert, vol. 7, pp. 21-26.

Hua, K., Faltings, B., (1993), "Exploring Case-Based Building Design - CADRE", AI EDAM, vol. 7, no. 2, pp. 135-143.

Irgens, C. I., (1995) "Design support based on projection of information across the product-development life cycle by means of case-based reasoning", IEE Proc.-Sci. Meas. Technol., vol. 142, No. 5.

Kolonder, J. L., (1993), Case-Based Reasoning, Morgan Kaufmann.

Leake, D. B., (1996) "CBR in Context: The Present and Future", in, Case-Based Reasoning: Experiences, Lessons, and Future Directions, ed. Leake, D. B., AAAI Press.

Maher, M., L., Balachandran, M., B., Zhang, D., M., (1995), Case-Based Reasoning in Design, Lawrence Erlbaum Associates, Inc..

Navinchandra, D., (1988), "Case-based reasoning in CYCLOPS, a design problem solver", in Proceedings: Workshop on case-based reasoning (DARPA), Clearwater, Florida. 
Prasad, B., (1996), Concurrent Engineering Fundamentals: Volume 1, Prentice Hall.

Ranky, P. G., (1994), Concurrent/Simultaneous Engineering, CIMware Ltd., 1994. Sanchez, S. M., Ramberg, J. S., Fiero, J., Pignatiello, J. J., (1993), “Quality by Design", in Concurrent Engineering: Automation, Tools, and Techniques, ed.

Kusiak, A., John Wiley \& Sons.

Schank, R., (1982), Dynamic Memory: A theory of Learning in Computers and People, Cambridge University Press.

.Simoudis, E., (1992), "Using Case-Based Retrieval for Customer Technical Support", IEEE Expert, vol. 7, pp. 7-13.

Sullivan, L. P., (1986), "Quality Function Deployment”, Quality Progress, June 1986.

Syncara, K., Navin Chandra, D., Guttal, R., Koning, J., Narasimhan, S., (1991), "CADET: A Case-Based Synthesis Tool for Engineering Design.", Int. Journal of Expert Systems, vol. 4, pt. 2.

Watson, I., (1995), "An introduction to Case-Based Reasoning", 1st UK Workshop on Case-Based Reasoning, BCS Specialist Group on Expert Systems, University of Salford, 12 January 1995.

Wendel, O., (1993), "Case-Based Reasoning in a Simulation Environment for Biological Neural Networks.”, First European Workshop, EWCBR-93,

Kaiserslautern, November 1-5.

Wilson, P. M., Greaves, J. G., (1990), "Forward Engineering - A strategic link between design and profit.", Mechatronic Systems Engineering, Vol. 1, No. 1. 